\title{
EDITORIAL
}

\section{Monitoring of pulmonary function in Pompe disease: a muscle disease with new therapeutic perspectives}

\author{
A.T. van der Ploeg
}

$\mathbf{M}$ onitoring of pulmonary function and timely initiation of noninvasive ventilation should be a focus in supportive care for patients with muscular disorders. In the current issue of the European Respiratory Journal, Pellegrini et al. [1] focus on this aspect in patients with lateonset Pompe disease (glycogenosis type II, acid maltase deficiency) [1]. In Pompe disease, correct monitoring of pulmonary function and initiation of supportive care is even more relevant since new therapeutic developments are underway. The first reports on the effects of enzyme therapy for this disease are promising [2-4].

Pompe disease is an autosomal, recessive, metabolic myopathy caused by deficiency of the lysosomal enzyme $\alpha$-glucosidase, which is involved in the degradation of glycogen. The disease has an estimated frequency of one in 40,000 and may present at any age $[5,6]$. Disease severity relates to the level of enzyme activity. Infants with a virtual absence of $\alpha$-glucosidase show symptoms shortly after birth. They do not reach major motor milestones, such as sitting and standing, due to progressive muscle weakness. A hypertrophic cardiomyopathy is characteristically present and classic infantile patients generally die before $1 \mathrm{yr}$ of age due to cardiorespiratory failure. Pompe disease may also occur in older children and adults. In this late-onset or nonclassic form of the disease, progression is much slower and patients finally become wheelchair bound and ventilator dependent. Interestingly, there is no strict order of what presents first, motor impairment or pulmonary insufficiency [7]. Although PeLleGriNI et al. [1] show that there is a relationship between deterioration of vital capacity and mobility they also indicate that this relationship is weak. Among the 19 patients they studied, six required ventilatory support while they were still able to walk up stairs. In the literature, various cases of late-onset Pompe disease have been reported in which respiratory insufficiency was the presenting symptom, while motor symptoms remained unnoticed [8]. Therefore, it is advised that pulmonary function be monitored routinely (yearly) in patients with late-onset Pompe disease, independent of their muscular function [1, 7]. Since diaphragmatic weakness is an important feature in Pompe disease, a significant postural drop may be found. Therefore, pulmonary function should not only be measured in sitting but both in upright and supine positions. In addition, polysomnograpy

CORRESPONDENCE: A.T. van der Ploeg, Dept of Paediatrics, Division of Metabolic Diseases, Erasmus MC Sophia Children's Hospital, University Medical Center, Dr. Molewaterplein 60, 3015 GJ Rotterdam, The Netherlands. Fax: 31 104636801. E-mail: vanderploeg@erasmusmc.nl and blood gas measurement may be helpful to diagnose nocturnal hypoventilation $[9,10]$.

There are limited data on the rate of disease progression in Pompe. Some patients may show a fast deterioration. In a recent questionnaire study performed in collaboration with the International Pompe Association, we found that in an international cohort of 225 late-onset patients, severity of disease, as measured by the percentage of patients requiring a wheelchair or ventilator, was mainly determined by disease duration and not by age. An exception to this rule was a subset of children presenting with the disease before the age of $15 \mathrm{yrs}$, who showed a more severe disease course [11].

Monitoring of disease progression and timely installation of supportive care becomes more and more relevant since the first results on enzyme therapy in Pompe disease indicate that the residual pulmonary function and/or motor function mainly determine the outcome of the patients. For infants with classic Pompe disease it has been shown that treatment with recombinant human $\alpha$-glucosidase significantly increases survival. In addition, a significant effect on cardiac hypertrophy was observed, leading to an improved cardiac function in all patients. However, the effect on both motor function and pulmonary function appeared highly dependent on the condition at the start of therapy. The first pilot study started in 1999 with recombinant human $\alpha$-glucosidase from rabbit milk, showing that the best performing patient out of four learned to walk independently at the age of 16 months, while two patients who started treatment at the end stage of disease did not reach major milestones $[2,12]$. Respiratory insufficiency could be prevented in the patient who performed best at the start but could not be reversed or prevented in the endstage patients. New larger studies sustain the findings, indicating the importance of early detection and diagnosis of classic infantile patients.

Although experience with enzyme therapy in late-onset Pompe disease is still limited, the first pilot study, started in 1999, showed similar effects [4]. Three patients, aged 11, 17 and $33 \mathrm{yrs}$, respectively, received therapy. All three patients were wheelchair bound and two patients were ventilator dependent. The ventilator-dependent patients had shown a significant deterioration of pulmonary function in the years before the start of treatment. Their forced vital capacity had decreased to 11 and $17 \%$, respectively, in sitting position and was immeasurable in supine position. One of the patients was completely ventilator dependent, while the other patient required ventilation for $18 \mathrm{~h}$ per day. During the course of 
treatment, deterioration of pulmonary function could be stopped in these patients and both became able to be spend more time per day off the ventilator ( $45 \mathrm{~min}$ for the $24 \mathrm{~h}$ ventilator dependent patient, while the other patients ventilator dependency decreased from 18 to $10 \mathrm{~h}$ per day), but there were no dramatic gains in vital capacity. Importantly, an age-related increase of pulmonary function could be maintained over the years in the best performing patient. Similar results were observed regarding the response of motor function. The more severely affected patients remained wheelchair bound and showed minimal improvements in muscle strength, while the best performing patient with substantial residual muscle function in his legs showed an impressive response to enzyme therapy. He could abandon his wheelchair during the course of treatment and learned to walk, ride a bicycle and even to play football.

With respect to supportive care, PELlegRINI et al. [1] indicate that installation of ventilatory support may cause a (temporary) improvement of pulmonary function during the initial months, which may interfere with assessing the effects of enzyme therapy. Unfortunately, the monitoring of pulmonary function after installation of mechanical ventilation was not systematically performed, but an explanation for their findings may be that patients sleep better and are less tired during the daytime through reversal of (nocturnal) hypoventilation. Furthermore, mechanical ventilation may alleviate the presence of micro-atelectasies, improve the evacuation of sputum and diminish the frequency of pulmonary infections.

In conclusion, although the effects of therapy in late-onset Pompe disease need further investigation, the current findings indicate that early detection of Pompe disease deserves attention, not only in the field of neurology but also in the field of pulmonology $[1,7,9,10,13]$. It should be noted that severe loss of pulmonary function may occur even in patients with minor mobility problems. Proper installation of noninvasive ventilation may help to maintain the physical functioning of the patients and prevent incidents of acute respiratory failure. Early detection of loss of respiratory muscle function may be relevant for decision making regarding the initiation of enzyme therapy in Pompe disease.

\section{REFERENCES}

1 Pellegrini N, Laforet P, Orlikowski D, et al. Respiratory insufficiency and limb muscle weakness in adults with acid maltase deficiency. Eur Respir J 2005; 26: 1024-1031.
2 Van den Hout JMP, Reuser AJJ, Vulto AG, Loonen MCB, Cromme-Dijkhuis A, Van der Ploeg AT. Recombinant human alpha-glucosidase from rabbit milk in Pompe patients. Lancet 2000; 356: 397-398.

3 Amalfitano A, Bengur AR, More RP, et al. Recombinant human acid alpha-glucosidase enzyme therapy for infantile glycogen storage disease type II: results of a phase I/II clinical trial. Genet Med 2001; 3: 132-138.

4 Winkel LPF, van den Hout JMP, Kamphoven JHJ, et al. Enzyme replacement therapy in late-onset Pompe's disease: a three-year follow-up. Ann Neurol 2004; 55: 495-502.

5 Hirschhorn R, Reuser AJJ. Glycogen storage disease type II; acid $\alpha$-glucosidase (acid maltase) deficiency. In: Scriver CR, Beadet A, Sly WS, Valle D, eds. The Metabolic and Molecular Bases of Inherited Disease. 8th Edn. Vol. III. New York, McGraw Hill, 2000; pp. 3389-3420.

6 Reuser AJJ, Kroos MA, Hermans MMP, et al. Glycogenosis type II (acid maltase deficiency). Muscle Nerve 1995; 3: S61-S69.

7 Hagemans MLC, Winkel LPF, Van Doorn PA, et al. Clinical manifestation and natural course of late-onset Pompe's disease in 54 Dutch patients. Brain 2005; 128: 671-677.

8 Winkel LPF, Hagemans MLC, Van Doorn PA, et al. The natural course of non-classic Pompe's disease: a review of 225 published cases. J Neurol 2005; 252: 875-884.

9 Mellies U, Stehling F, Dohna-Schwake C, Ragette R, Teschler H, Voit T. Respiratory failure in Pompe's disease: treatment with noninvasive ventilation. Neurology 2005; 64: 1465-1467.

10 Mellies U, Ragette R, Schwake C, Baethmann M, Voit T, Teschler H. Sleep-disordered breathing and respiratory failure in acid maltase deficiency. Neurology 2001; 57: 1290-1295.

11 Hagemans MLC, Janssens ACJW, Winkel LPF, et al. Lateonset Pompe disease primarily affects quality of life in physical health domains. Neurology 2004; 63: 1688-1692.

12 Van den Hout JMP, Kamphoven JHJ, Winkel LPF, et al. Long-term intravenous treatment of Pompe disease with recombinant human alpha-glucosidase from milk. Pediatrics 2004; 113: e448-e457.

13 Wokke JH, Ausems MG, van den Boogaard MJ, et al. Genotype-phenotype correlation in adult-onset acid maltase deficiency. Ann Neurol 1995; 38: 450-454. 